\title{
Green Expedient Synthesis of Pyrimidine Derivatives via Chalcones and Evaluation of their Anthelmintic Activity
}

\author{
Biswa Mohan Sahoo ${ }^{1 *}$, Mullangi Rajeswari', Panda Jnyanaranjan², Sahoo Binayani ${ }^{3}$ \\ 1'Department of Pharmaceutical Chemistry, Vikas College of Pharmacy, Vissannapeta, Krishna District, Andhra Pradesh, INDIA. \\ ${ }^{2}$ Department of Medicinal Chemistry, Roland Institute of Pharmaceutical Sciences, Khodasingi, Berhampur, Odisha, INDIA. \\ ${ }^{3}$ Department of Chemistry, M.V.R Degree College,Nuzvid, Krishna University, Andhra Pradesh, INDIA.
}

\begin{abstract}
Objective: In the present study, we focused on the environment-friendly processes used for the preparation of pyrimidine derivatives with pharmacological properties. In this regard, microwave heating is used as the alternative energy sources to synthesize a series of pyrimidine derivatives by the condensation of chalcones with urea under basic conditions. Chalcones were synthesized by Claisen-Schimidt condensation of acetophenone with various substituted benzaldehyde in the presence of ethanolic potassium hydroxide solution. Methods: The IR, ${ }^{1} \mathrm{H}-\mathrm{NMR}$, mass spectra and $\mathrm{CHN}$ analyses confirmed the structure of the prepared compounds. Shorter reaction time, environment friendly procedure and excellent yields are the advantages of microwave synthesis. The newly synthesized pyrimidine derivatives were screened for their anthelmintic activity and found to have moderate to considerable activity as compared to the standard drug. Results: Some of the synthesized compounds exhibited significant anthelmintic activity. Compound $4 \mathrm{e}$ with electron withdrawing groups was found to be highly potent among the series. This attempt will lead to an increased number of new and sustainable methods for the synthesis of biologically-active pyrimdine derivatives.
\end{abstract}

Keywords: Anthelmintic activity, Chalcone, Claisen-schmidt reaction, Green synthesis, Pyrimidine.

\section{INTRODUCTION}

Chalcones are $\alpha, \beta$-unsaturated ketones consisting of two aromatic rings such as ring $A$ and B. Both rings are interconnected by a highly electrophilic three carbon $\alpha$, $\beta$-unsaturated carbonyl system that assumes linear or planar structure. ${ }^{1,2}$ They possess conjugated double bonds and a completely delocalized $\pi$-electron system on both benzene rings. Chemically, chalcone is 1,3-diphenyl2-propene-1-one. These are coloured compounds due to presence of the chromophore, ketoethylenic group (-CO-CH=CH-) in their structure. ${ }^{3,4}$ The structure of chalcone with plane, centroid and exclusion sphere is shown in the Figure 1. The energy minimized 3D structure of chalcone is presented in the Figure 2. Chalcones are synthesized by claisen-schmidt condensation of ketone with different aromatic aldehydes by strong bases $(\mathrm{NaOH} / \mathrm{KOH})$ or acid catalyzed followed by dehydration process. ${ }^{5,6}$ The presence of reactive $\alpha, \beta$-unsaturated keto group in chalcones is found to be responsible for producing their biological activity. ${ }^{7}$ Chalcone derivatives are considered as key starting materials for the syntheses of different classes of heterocyclic compounds such as pyrazolines, oxazoles, isoxazoles, thiophenes and pyrimidines, etc. ${ }^{8,9}$ Among the heterocyclic compounds, Pyrimidine derivatives are valuable heteroaromatic compounds because of their wide spectrum of pharmacological applications such as antimalarial, anthelmintic, anticancer,
Submission Date: 20-07-2017; Revision Date: 17-09-2017; Accepted Date: 23-11-2017

DOI: 10.5530/ijper.51.4s.101 Correspondence:

Biswa Mohan Sahoo, Department of Medicinal Chemistry, Vikas College of Pharmacy, Vissannapeta, Krishna District, Andhra Pradesh, INDIA.

Tel: +91-9133055582 E-mail: drbiswamohansahoo@gmail.com

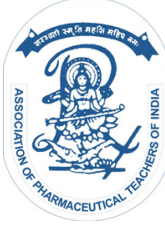

www.ijper.org 
antimicrobial, anti-convulsion and anti-inflammatory activities. ${ }^{10-12}$ Numerous methods have been reported to prepare pyrimidine derivatives. ${ }^{13,14}$ However, these reported methods suffered from drawbacks such as longer reaction time, complicated work up procedures, use of acids or bases and hazardous solvents. ${ }^{15,16}$ Thus, the use of microwave energy for the synthesis of new drug molecules follows green chemistry approach. ${ }^{17-19}$ Out of the various principles of green chemistry, the important one is the maximization of the atom economy which evaluates the efficiency of chemical transformation of reactant materials and is calculated as follow. ${ }^{20-22}$

$$
\begin{aligned}
& \text { Molecular weight of } \\
& \begin{aligned}
\% \text { Atom utilization }= & \frac{\text { desired product }}{\text { Molecular weight of desired }} \times 100 \\
& \text { product }+ \text { waste product }
\end{aligned}
\end{aligned}
$$

In the present study and as a part of our project, we have planned to prepare pyrimidine derivatives using both conventional as well as microwave induced heating methods and to study their anthelmintic activity. ${ }^{23-25}$

\section{Chemistry}

Pyrimidine derivatives (4a-e) were prepared via chalcones by the treatment of chalcones with urea in the presence of ethanolic potassium hydroxide solution. Claisen-Schimidt condensation mechanism is followed to synthesize chalcones (3a-e) by reaction of acetophenone (2) with various substituted benzaldehyde (1a-e) in the presence of ethanolic potassium hydroxide solution as presented in Figure 3 and scheme-1..$^{26-28}$

\section{EXPERIMENTAL METHOD}

All chemicals were of synthetic grade (S. D. Fine. Chem. Ltd. Mumbai, India). Both conventional and microwave synthesis was carried out to compare reaction time and yield of product. The microwave irradiated synthesis was performed in scientific microwave oven, Catalyst System (operating between 140-700 W). All the reactions were carried out at power level-2, which corresponds to $210 \mathrm{~W}$. The synthesized products were recrystallized from ethanol as a solvent. Melting points were determined in open capillary tubes, expressed in ${ }^{0} \mathrm{C}$ and are uncorrected. The time required for completion of the reaction and the purity of the compounds were checked by ascending TLC using pre-coated Silica gel-G plates and spots were observed by exposure to iodine vapours or by UV light at 254 and $366 \mathrm{~nm}$. The compounds were characterized by using IR, ${ }^{1} \mathrm{H}$ NMR, Mass spectral and Elemental analysis. The IR spectra of
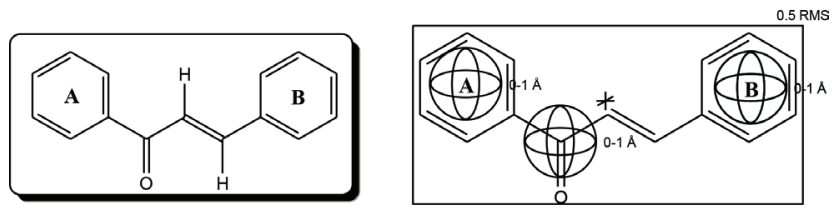

Figure 1: Structure of chalcone showing plane, centroid and exclusion sphere.

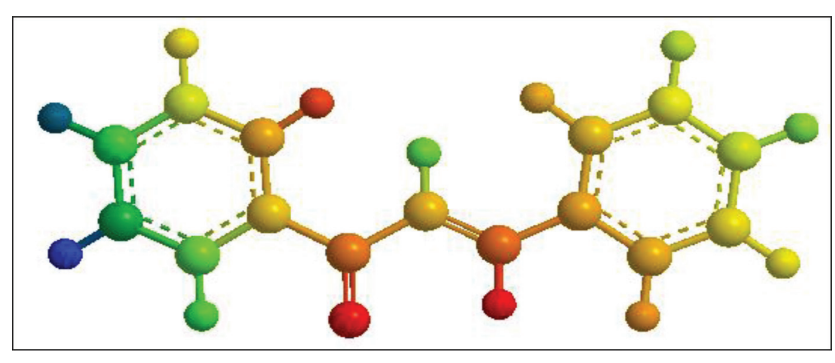

Figure 2: Energy minimized 3D structure of chalcone.

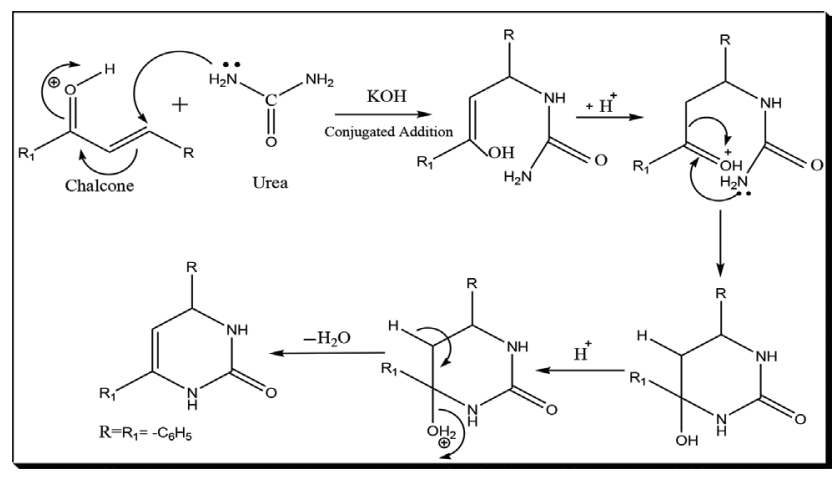

Figure 3: Reaction mechanism involved in formation of pyrimidine via chalcone.

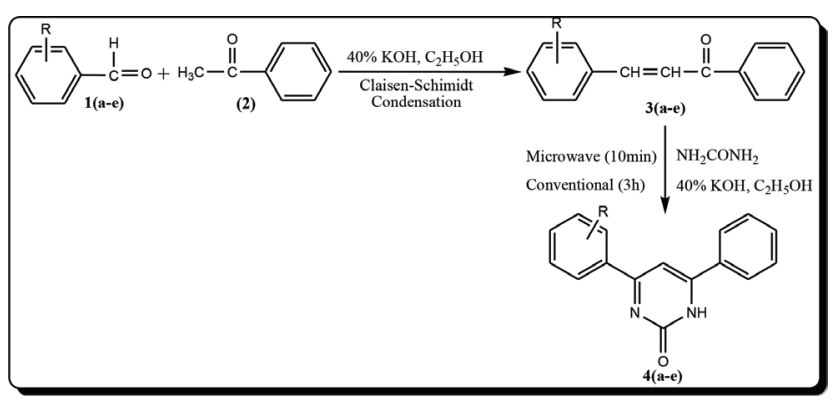

Scheme 1: Synthesis of pyrimidine derivatives.

the compounds were recorded on Shimadzu IR Affinity FT-IR using $\mathrm{KBr}$ discs and the values are expressed in $\mathrm{cm}^{-1}$. The ${ }^{1} \mathrm{HNMR}$ spectra were recorded on a Bruker AC $400 \mathrm{MHz}$ spectrometer using TMS as the internal standard in DMSO- $d 6$. The multiplicities of the signals are denoted with the symbols $s, d$, $t$ and $m$ for singlet, doublet, triplet and multiplet, respectively. The LC-MS spectra were recorded on Waters Micromass Q-Tof Micro $(70 \mathrm{eV})$, a hybrid quadrupole time of flight mass 
Table 1: Elemental analysis of titled compounds (4a-e)

\begin{tabular}{|c|c|c|c|c|c|c|c|c|c|}
\hline \multirow[t]{3}{*}{ Compound Code } & \multirow{3}{*}{$\begin{array}{l}\text { Molecular } \\
\text { formula }\end{array}$} & \multicolumn{8}{|c|}{ Elemental Analysis (\%) } \\
\hline & & \multicolumn{4}{|c|}{ Calculated } & \multicolumn{4}{|c|}{ Found } \\
\hline & & C & H & $\mathbf{N}$ & 0 & C & H & $\mathbf{N}$ & 0 \\
\hline $4 a$ & $\mathrm{C}_{16} \mathrm{H}_{12} \mathrm{~N}_{2} \mathrm{O}$ & 77.40 & 4.87 & 11.28 & 6.44 & 77.33 & 4.85 & 11.23 & 6.43 \\
\hline $4 b$ & $\mathrm{C}_{16} \mathrm{H}_{11} \mathrm{~N}_{3} \mathrm{O}_{3}$ & 65.53 & 3.78 & 14.33 & 16.37 & 65.20 & 3.69 & 14.36 & 16.39 \\
\hline $4 c$ & $\mathrm{C}_{16} \mathrm{H}_{11} \mathrm{~N}_{3} \mathrm{O}_{3}$ & 65.53 & 3.78 & 14.33 & 16.37 & 65.80 & 3.79 & 14.30 & 16.38 \\
\hline 4d & $\mathrm{C}_{16} \mathrm{H}_{12} \mathrm{~N}_{2} \mathrm{O}_{2}$ & 72.72 & 4.58 & 10.60 & 12.11 & 72.18 & 4.71 & 10.63 & 12.09 \\
\hline $4 e$ & $\mathrm{C}_{16} \mathrm{H}_{12} \mathrm{~N}_{2} \mathrm{O}_{2}$ & 72.72 & 4.58 & 10.60 & 12.11 & 72.90 & 4.54 & 10.58 & 12.10 \\
\hline
\end{tabular}

spectrometer. Elemental analyses of the newly synthesized compounds were carried out on Carlo Erba 1108 analyzer and values are given in Table 1.

\section{Synthesis of chalcones $3(a-e)$}

Substituted benzaldehydes (1a-e) $(0.01 \mathrm{~mol})$ and acetophenone (2) (0.01 mol, $1.2 \mathrm{~g})$ were mixed and dissolved in ethanol $(10 \mathrm{~mL})$. To this, $40 \%$ aqueous solution of potassium hydroxide $(10 \mathrm{ml})$ was added slowly with constant stirring. The reaction mixture was stirred continuously for $3 \mathrm{~h}$ at room temperature. The completion of reaction was confirmed by monitoring TLC using silica gel-G. After completion of the reaction, the reaction mixture was kept in refrigerator overnight. The product was filtered and washed with cold water till the washings were neutral to litmus, if necessary acidified with dilute $\mathrm{HCl}$. The product was dried and recrystallized from rectified spirit to get pale yellow colored solid chalcones (3a-e).

\section{Syntheses of 4-(substituted-phenyl)-6-phenyl- pyrimidin-2(1H)-one (4a-e)}

\section{Conventional synthesis}

A mixture of chalcone (3a-e) $(0.01 \mathrm{~mol})$, urea $(0.01$ mol, $0.6 \mathrm{~g})$ were dissolved in ethanol $(10 \mathrm{~mL}, 95 \%)$. To this, $40 \%$ aqueous potassium hydroxide solution $(10 \mathrm{~mL})$ was added slowly with constant stirring. The reaction mixture was allowed to reflux on water bath for $4 \mathrm{~h}$. In between TLC was monitored to check the completion of reaction. After completion of reaction, the reaction mixture was cooled to room temperature and then poured into ice cold water and neutralized by adding dilute $\mathrm{HCl}$. The precipitate (4a-e) obtained was filtered, washed with water and dried. The product was recrystallized from rectified spirit.

\section{Microwave synthesis}

A mixture of chalcone (3a-e) $(0.01 \mathrm{~mol})$, urea $(0.01 \mathrm{~mol}$, $0.6 \mathrm{~g})$ were dissolved in ethanol $(10 \mathrm{~mL}, 95 \%)$. To this, $40 \%$ aqueous potassium hydroxide solution $(10 \mathrm{~mL})$ was added slowly with constant stirring. The reaction mixture was placed in microwave and irradiated at power level-2 $(210 \mathrm{~W})$ for 7-10 min. In between, TLC was monitored to check the completion of reaction condition. After completion of reaction, the reaction mixture was cooled to room temperature and then poured into ice cold water and neutralized by adding dilute $\mathrm{HCl}$. The precipitate obtained was filtered, washed with water and dried. The product (4a-e) was recrystallized from rectified spirit.

\section{4,6-diphenyl-pyrimidin-2(1H)-one (4a)}

IR $\left(v, \mathrm{~cm}^{-1}\right): 3308$ (Pyrimidine-NH Str), 1655 (C=O Str), 2983 (Ar. C-H Str). ${ }^{1} \mathrm{H}-\mathrm{NMR}(400 \mathrm{MHz}, \mathrm{DMSO}-d \sigma) \delta$ (ppm): 3.46 (s,1H, -CH of Pyrimidine ring), 6.31-7.93 (m,10H,Ar-H),7.95 (s,1H,-NH). MS, m/z (\%): Found for $\mathrm{C}_{16} \mathrm{H}_{12} \mathrm{~N}_{2} \mathrm{O}: 248.26$.

\section{4-(3-nitro-phenyl)-6-phenyl-pyrimidin-2(1H)-one} (4b)

IR $\left(v, \mathrm{~cm}^{-1}\right): 3320$ (Pyrimidine-NH Str), $1650(\mathrm{C}=\mathrm{O}$ (Str), 2923 (Ar.C-H (Str), 1606(-NO2 Str). ${ }^{1} \mathrm{H}-\mathrm{NMR}$ (400 MHz, DMSO-d6) $\delta(\mathrm{ppm}): 3.61(\mathrm{~s}, 1 \mathrm{H},-\mathrm{CH}$ of Pyrimidine ring), 7.36-8.02 (m, 9H, Ar-H), 8.24 (s, $1 \mathrm{H}$, -NH). MS, $\mathrm{m} / \mathrm{z}(\%)$ : Found for $\mathrm{C}_{16} \mathrm{H}_{11} \mathrm{~N}_{3} \mathrm{O}_{3}: 293.4$.

\section{4-(4-nitro-phenyl)-6-phenyl-pyrimidin-2(1H)-one} (4c)

IR $\left(v, \mathrm{~cm}^{-1}\right): 3326$ (Pyrimidine-NH Str), $1654(\mathrm{C}=\mathrm{O}$ (Str), 2926 (Ar.C-H (Str), 1608 (-NO 2 Str). ${ }^{1} \mathrm{H}-\mathrm{NMR}$ $(400 \mathrm{MHz}, \mathrm{DMSO}-d \sigma) \delta(\mathrm{ppm}): 3.63(\mathrm{~s}, 1 \mathrm{H},-\mathrm{CH}$ of Pyrimidine ring), 7.24-8.14 (m, 9H, Ar- $\mathrm{H}), 8.32$ (s, 1H, -NH). MS, m/z (\%): Found for $\mathrm{C}_{16} \mathrm{H}_{11} \mathrm{~N}_{3} \mathrm{O}_{3}: 293.5$.

\section{4-(2-hydroxy-phenyl)-6-phenyl-pyrimidin-2(1H)- one $(4 d)$}

IR $\left(v, \mathrm{~cm}^{-1}\right): 3247$ (Pyrimidine-NH Str), 1647 (C=O Str), 2933 (Ar.C-H Str), 3362 (-OH Str). ${ }^{1} \mathrm{H}-\mathrm{NMR}(400 \mathrm{MHz}$, DMSO-do) $\delta$ (ppm): 3.34 (s, $1 \mathrm{H}$, $-\mathrm{CH}$ of pyrimidine ring), 6.83-7.98 (m, 9H, Ar-H), $8.13(\mathrm{~s}, 1 \mathrm{H},-\mathrm{NH}), 10.10$ (s, $1 \mathrm{H},-\mathrm{OH})$. MS, m/z (\%): Found for $\mathrm{C}_{16} \mathrm{H}_{12} \mathrm{~N}_{2} \mathrm{O}_{2}$ : 264.19. 


\begin{tabular}{|c|c|c|c|c|}
\hline \multirow[t]{2}{*}{ SI. No. } & \multirow[t]{2}{*}{ Compounds } & \multirow[t]{2}{*}{ Dose } & $\begin{array}{l}\text { Paralysis time } \\
\text { (Minute) }\end{array}$ & Death time (Minute) \\
\hline & & & Mean士S.E.M & Mean士S.E.M \\
\hline 1 & $4 a$ & $100 \mathrm{mg} / \mathrm{mL}$ & $25 \pm 0.5$ & $30 \pm 0.41$ \\
\hline 2 & $4 b$ & $100 \mathrm{mg} / \mathrm{mL}$ & $29 \pm 0.529$ & $33 \pm 0.36$ \\
\hline 3 & $4 c$ & $100 \mathrm{mg} / \mathrm{mL}$ & $30 \pm 0.763$ & $34 \pm 0.61$ \\
\hline 4 & $4 d$ & $100 \mathrm{mg} / \mathrm{mL}$ & $27 \pm 0.76$ & $32 \pm 0.8$ \\
\hline 5 & $4 e$ & $100 \mathrm{mg} / \mathrm{mL}$ & $25 \pm 0.36$ & $35 \pm 0.72$ \\
\hline 6 & $3 a$ & $100 \mathrm{mg} / \mathrm{mL}$ & $20 \pm 1.2$ & $22 \pm 0.78$ \\
\hline 7 & $\begin{array}{c}\text { Control } \\
\text { (Normal saline) }\end{array}$ & ------- & ------- & ------ \\
\hline 8 & Albendazole & $100 \mathrm{mg} / \mathrm{mL}$ & $17 \pm 1.1$ & $21 \pm 2.1$ \\
\hline
\end{tabular}

\section{4-(4-hydroxy-phenyl)-6-phenyl-pyrimidin-2(1H)-} one $(4 \mathrm{e})$

IR $\left(v, \mathrm{~cm}^{-1}\right): 3378$ (Pyrimidine $-\mathrm{NH}$ Str), $1648(\mathrm{C}=\mathrm{O}$ Str), 2926 (Ar.C-H Str), 3420 (-OH Str). ${ }^{1} \mathrm{H}-\mathrm{NMR}$ (400 MHz, DMSO-d6) $\delta$ (ppm): 3.33 (s, $1 \mathrm{H},-\mathrm{CH}$ of pyrimidine ring), 6.86-7.88 (m, 9H, Ar-H), 8.11 (s, 1H, $-\mathrm{NH}), 10.28$ (s, 1H,-OH). MS, m/z (\%): Found for $\mathrm{C}_{16} \mathrm{H}_{12} \mathrm{~N}_{2} \mathrm{O}_{2}: 264.23$.

\section{Anthelmintic Activity}

Helminthiasis is a macroparasitic disease found in humans due to parasitic worms such as Nematodes or Cestodes which are present in skin, liver, brain, lungs, lymph, eye, muscles etc. of the body. The marketed anthelmintic drugs are used to expel such parasitic worms from the body by either stunning or killing them without causing any significant damage to the host cell. Pyrimidine derived drugs such as pyrantel and morantel are commonly used as anthelmintic agents which has broad spectrum activity. Indian adult earthworms were selected to study the antihelmintic activity. The earthworms were collected from the water logged areas of soils in Vissannapeta, Andhra Pradesh, India. Earthworms were washed with normal saline to remove all the fecal matter and waste surrounding their body. The earth worms (Pheritima posthuma) 5-8 $\mathrm{cm}$ in length and 0.2-0.3 cm width weighing 0.8-3.04 $\mathrm{g}$ were used for experimental protocols. As the earthworms are resembled anatomically and physiologically with the intestinal roundworm parasites of human beings, hence they were selected to study the anthelmintic activity. ${ }^{29}$

\section{Procedure}

Gum acacia solution (1\%) was prepared by using normal saline. Test solutions $(100 \mathrm{mg} / \mathrm{ml})$ were prepared by using Gum acacia solution. Samples were taken in petriplates and adult healthy earth warms $(n=6)$ were introduced into petriplates. Observations were made for the time taken to paralyze and time taken for death of the earthworms. Paralysis was said to occur when the worms do not revive even in normal saline. Death was concluded when worms lost their motility followed by fading away of the body color and the values are summarized in Table 2 and presented in Figure 4.

\section{RESULTS AND DISCUSSION}

The chalcones were prepared by the Claisen Schmidt condensation of acetophenone (2) with various substituted benzaldehyde (1a-e) in the presence of ethanolic potassium hydroxide solution. Both conventional as well as microwave assisted methods followed to prepare a series of pyrimidine derivatives via chalcones by the treatment of chalcones with urea in basic media (Scheme I). The prepared compounds along with their reaction time period and percentage yields were given in Table 3. It was found that the microwave assisted method is energetically favourable which requires less time with enhanced reaction rates and provides better yields $(79-85 \%)$ with pure product as compared to

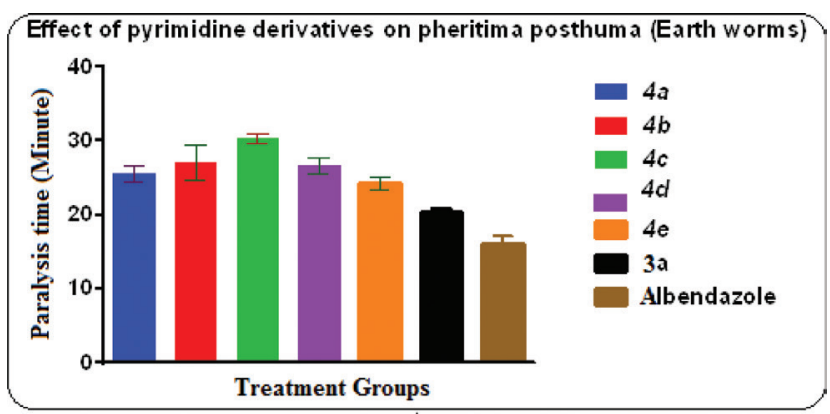

Figure 4: Anthelmintic activity (paralysis time) of titled compounds. 


\section{Table 3: Physical characterization data and comparison between conventional and microwave assisted} synthesis of pyrimidine derivatives (4a-e)

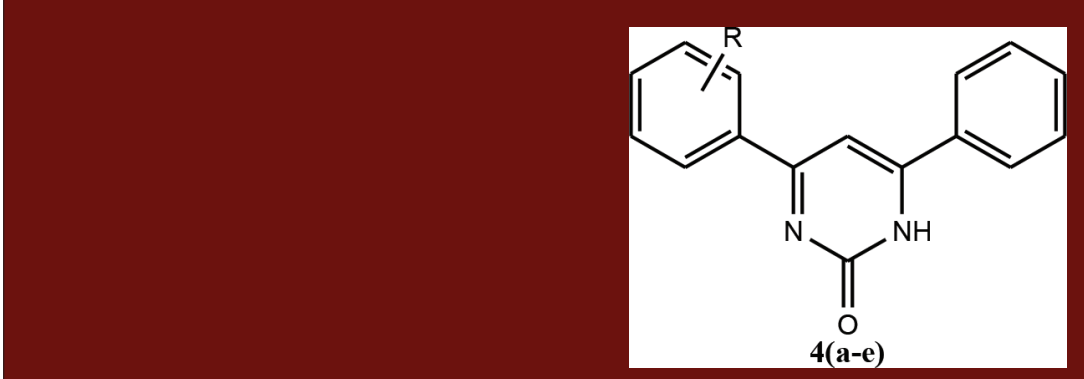

\begin{tabular}{|c|c|c|c|c|c|c|c|c|c|c|}
\hline \multirow{2}{*}{$\begin{array}{l}\text { Comp. } \\
\text { Code }\end{array}$} & \multirow[t]{2}{*}{ Structure (R) } & \multirow[t]{2}{*}{$R_{f}$ Value } & \multirow[t]{2}{*}{ M.P. $\left({ }^{\circ} \mathrm{C}\right)$} & \multicolumn{3}{|c|}{ Conventional Method } & \multicolumn{4}{|c|}{ Green Synthesis (Microwave) Method } \\
\hline & & & & $\begin{array}{l}\text { Time } \\
\text { (h) }\end{array}$ & $\begin{array}{c}\text { Energy } \\
\left(\text { Temp. }{ }^{\circ} \mathrm{C}\right)\end{array}$ & $\begin{array}{c}\text { Yield } \\
(\%)\end{array}$ & $\begin{array}{l}\text { Time } \\
\text { (min.) }\end{array}$ & $\begin{array}{c}\text { Energy } \\
\text { (Power. } \\
\text { Watt) }\end{array}$ & Yield (\%) & $\begin{array}{c}\text { Atom } \\
\text { Economy }\end{array}$ \\
\hline $4 a$ & $\mathrm{H}$ & 0.62 & $90-93$ & 3 & $98-100$ & 58.67 & 7 & 210 & 79.48 & $67.52 \%$ \\
\hline $4 b$ & $3-\mathrm{NO}_{2}$ & 0.63 & $201-204$ & 4 & $98-100$ & 60.85 & 9 & 210 & 82.73 & $71.47 \%$ \\
\hline $4 c$ & $4-\mathrm{NO}_{2}$ & 0.65 & $176-179$ & 4 & $98-100$ & 62.85 & 8 & 210 & 82.33 & $69.35 \%$ \\
\hline $4 d$ & $2-\mathrm{OH}$ & 0.57 & $197-200$ & 4 & $98-100$ & 65.31 & 10 & 210 & 85.25 & $72.83 \%$ \\
\hline $4 e$ & $4-\mathrm{OH}$ & 0.51 & $185-190$ & 3 & $98-100$ & 62.56 & 9 & 210 & 81.66 & $68.28 \%$ \\
\hline
\end{tabular}

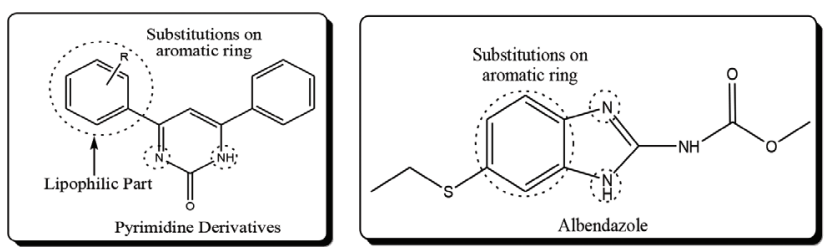

Figure 5: Pharmacophoric requirements for anthelmintic activity.

conventional synthesis (yield 58-65\%). All the synthesized compounds were soluble in methanol, ethanol, and dimethyl sulphoxide and insoluble in nonpolar solvents. The structures of prepared pyrimidine derivatives have been elucidated by spectroscopic data and elemental analysis. The synthesized compounds were analyzed by their physical and chromatographic parameters. Further analysis by IR, NMR, and Mass spectroscopy was carried out to interpret the structure of the above synthesized compounds. The mobile phase selected for TLC study was n-hexane: ethyl acetate (70:30). The spectra of chalcones show usually a peak, near $1625-1650 \mathrm{~cm}^{-1}$, characteristic of $\alpha, \beta$ unsaturated carbonyl group. The $\alpha-\mathrm{H}$ and $\beta-\mathrm{H}$ of chalcones resonate at $\delta$ 6.7-7.4 and $\delta$ 7.3-7.7 as two doublets $\left(\mathrm{J}=17 \mathrm{H}_{2}\right)$ in the ${ }^{1} \mathrm{H}$ NMR spectra. The IR spectrum of pyrimidine derivatives (4a-e) showed absorption at $\lambda_{\text {max }} 2923-2983 \mathrm{~cm}^{-1}$ (Ar-C-H), 1344 and $1606 \mathrm{~cm}^{-1}$ (Ar-NO $), 1647-1690$ (C=O Str), 3247-3378 $\mathrm{cm}^{-1}-3308$ (pyrimidine-NH Str.), 3362-3420 (Ar-OH) respectively. In the ${ }^{1} \mathrm{H}$ NMR spectrum, the proton of the $-\mathrm{CH}$ and $-\mathrm{NH}$ of pyrimidine nucleus resonated as a sharp singlet at $\delta 3.61$ and 8.24 respectively. The aromatic protons were seen as a multiple at $\delta 6.74-8.02$. The mass spectra of the pyrimidine derivatives exhibited molecular ion peak corresponding to their molecular formula. Compound $4 \mathrm{~b}$ and $4 \mathrm{c}$ showed molecular ion peak at $\mathrm{m} / \mathrm{z}$. 293.4 and 293.5 respectively. All the synthesized compounds showed significant anthelmintic activity. Among the tested compounds, $4 \mathrm{e}$ showed potential anthelmintic activity $25 \pm 0.36$ and $35 \pm 0.72 \mathrm{~min}$ for paralysis and death respectively as compared to the standard drug.

\section{STRUCTURE ACTIVITY RELATIONSHIP (SAR) STUDY}

The structure-activity relationship study is based on the above results which indicate that compounds with electron withdrawing groups on the aromatic ring showed increased potency. The presence of various substitutions such as hydroxy, methoxy, nitro groups on ring provides significant activity. Hence, it clearly indicates that the position and number of substituents in the compounds is responsible for increased in their biological activity as presented in Figure 5. The intense in activity of the compounds is also greatly influenced by the amount of activation or deactivation and position of the groups on the ring. ${ }^{30}$

\section{CONCLUSION}

In an attempt to develop new class of anthelmintic agents, a series of pyrimidine derivatives were efficiently synthesized with good yield and purity in less reaction time by microwave irradiated method as compared to 
conventional heating technique. Microwave irradiated synthesis is an invaluable technology which made the chemical reaction simple, rapid and eco-friendly to get the cleaner products. By the help of microwave synthesis, the yield of product was increased from 58\% upto 85\% as compared to conventional synthesis which signifies the utility of green chemistry approach. Some of the synthesized compounds showed significant anthelmintic activity. Compound $4 \mathrm{e}$ with electron withdrawing groups was found to be highly potent among the series. Thus, the quest to explore many more modifications on chalcone and pyrimidine moiety needs to be continued.

\section{ACKNOWLEDGEMENT}

Declared none.

\section{CONFLICT OF INTEREST}

There is no conflict of interests regarding the publication of this research paper.

\section{ABBREVIATION USED}

Comp: Compounds; ${ }^{\circ} \mathbf{C}$ : degree centigrade; ${ }^{1} \mathbf{H}$ NMR: Proton Nuclear Magnetic Resonance; I.R: Infrared Spectroscopy; $\mathbf{K B r}$ : Potassium Bromide; $\mu \mathrm{g}$ : micro gram; mL: milli liter; min: minute; mm: milli miter; M.p: Melting point; MWI: Microwave irradiation; ppm: parts per million; $\mathbf{R}_{\mathbf{f}}$ : Retention factor; str: Stretching; TLC: Thin Layer Chromatography; TMS: Tetra methyl silane; W: Watt.

\section{REFERENCES}

1. Patil CB, Mahajan SK, Katti SA. Chalcone: A Versatile Molecule. J Pharm Sci and Res. 2009;1(3):11-22.

2. Nidhi S, Ahmad S, Alam MS. Biological Potentials of Chalcone: A Review. Int $\mathrm{J}$ of Pharm and Biolog Arch. 2012;3(6):1298-303.

3. Trivedi AR, Dodiya DK, Ravat NR, Shah VH. Synthesis and biological evaluation of some new pyrimidines via novel chalcone series. ARKIVOC. 2008;11(1):131-41.

4. Kachroo M, Panda R, Yadav Y. Synthesis and biological activities of some new pyrimidine derivatives from chalcones. Der Pharma Chemica. 2014;6(2):352-9

5. Ahmed MA. Synthesis, characterization and antibacterial activity of (E)+Chalcone derivatives. Eur. J. Chem. 2013;4(3):207-10.

6. Jyothi MV, Prasad YR, Venkatesh P, Reddy MS. Synthesis and Antimicrobial Activity of Some Novel Chalcones of 3-acetyl Pyridine and their Pyrimidine Derivatives. Chem. Sci. Trans. 2012;1(3):716-22.
7. Jin $\mathrm{C}$, Liang $\mathrm{Y}, \mathrm{He} \mathrm{H}, \mathrm{Fu} \mathrm{H}$. Synthesis and antitumor activity of novel chalcone derivatives. Biomedicine and Pharma. 2013;67(3):215-7.

8. Kachroo M, Panda R, Yadav Y. Synthesis and biological activities of some new pyrimidine derivatives from chalcones. Pharm. Chem. 2014;6(2):352-9.

9. Dudhe R, Sharma PK, Verma PK. Synthesis and biological activities of some new pyrimidine derivatives from chalcones. Int J Res Dev Pharm Life Sci. 2015;4:1.

10. Verma A., Sahu L, Chaudhary N, Dutta T, Dewangan D, Tripathi DK. A Review: pyrimidine their chemistry and pharmacological potentials. Asian Journal of Biochemical and Pharmaceutical Research. 2012;1(2):1-15.

11. Arikkatt SD, Baldwin MV, Joseph J, Chandran M, Bhat AR, Kumar K. Pyrimidine derivatives and its biological potential-A review. Int $\mathrm{J}$ of Org and Bio org Chem. 2014;4(1):1-5

12. Dansena $\mathrm{H}$, Dhongade $\mathrm{HJ}$, Chandrakar $\mathrm{K}$. Pharmacological potentials of pyrimidine derivative: A Review. Asian J Pharm Clin Res. 2015;8(4):171-7.

13. Kaur N, Aggarwal AK, Sharma N, Choudhary B. Synthesis and in-vitro antimicrobial Activity of pyrimidine derivatives. Int $\mathrm{J}$ of Pharm Sci and Drug Res. 2012;4(3):199-204.

14. Mohana KN, Basavapatna N, Mallesha L. Synthesis and biological activity of some pyrimidine derivatives. Drug Invent. 2013;5(3):216-22.

15. Gupta YK, Gupta V, Singh S. Synthesis, characterization and antimicrobial activity of pyrimidine based derivatives. J Pharm Res. 2013;7(6):491-5.

16. Hussaina MMM, Bhat KI, Revanasiddappa BC, Bharathi DR. Synthesis and biological evaluation of some novel 2-mercapto pyrimidines. Int J Pharm Pharm Sci. 2013;5(2):471-3

17. Bansal S, Chaudharya AN, Kothiyal P. Microwave assisted synthesis and antibacterial activity of pyrimidine derivatives. Int J Pharm Pharm Sci. 2014;5(1):346-8.

18. Madhavi A, Surati SJ, Desai KR. A brief review: Microwave assisted organic reaction, Arch. Appl Sci Res. 2012;4(1):645-61.

19. Ravichandran R, Karthikeyan E. Microwave synthesis-A potential tool for green chemistry. Int J Chem Tech Res. 2011;3(1):466-70.

20. Anastas P, Eghbali N. Green chemistry: principles and practice. Chem Soc Rev. 2010;39(1):301-12.

21. Sheldon RA. Fundamentals of green chemistry: efficiency in reaction design. Chem Soc Rev. 2012;41(4):1437-51.

22. Kappe CO, Dallinger D. The impact of microwave synthesis on drug discovery. Nature Rev. Drug Discov. 2006;5(1):51-63.

23. Gedye R, Smith F, Westaway K, Ali H, Baldisera L, La-berger L, et al. The use of microwave ovens for rapid organic synthesis. Tetrahedron Lett. 1986;27(3):279-82.

24. Kappe CO. Controlled microwave heating in modern organic synthesis. Angew. Chem. Int Ed. 2004;43(46):6250-84.

25. Dunn PJ. The importance of green chemistry in process research and development. Chem Soc Rev. 2012;41(4):1452-61.

26. Kaur N, Aggarwal AK, Sharma N, Choudhary B. Synthesis and in-vitro antimicrobial activity of pyrimidine derivatives. Int $\mathrm{J}$ Pharm Sci Drug Res. 2012;4(3):199-204.

27. Hartung CG, Backes AC, Felber B, Missio A, Philipp, A. Efficient microwaveassisted synthesis of highly functionalized pyrimidine derivatives. Tetrahedron. 2006;62(43):10055-64.

28. Majumder A, Gupta R, Jain A. Microwave-assisted synthesis of nitrogencontaining heterocycles. Green Chem. Lett. Rev. 2013;6:151-82.

29. Shruthi N, Poojary B, Kumar V, Bhat M, Joshi H, Revanasiddappa BC. Synthesis, molecular properties and evaluation of anthelmintic activity of new thiazolopyrimidine derivatives. J. of Chem. and Pharm. Res. 2015;7(6):181-91.

30. Singh K, Kaur H, Chibale K, Balzarini J, Little S, Bharatam PV. 2-aminopyrimidine based 4-aminoquinoline anti-plasmodial agents. Synthesis, biological activity, structure-activity relationship and mode of action studies. Eur. J. Med. Chem. 2012;52:82-97. 
PICTORIAL ABSTRACT
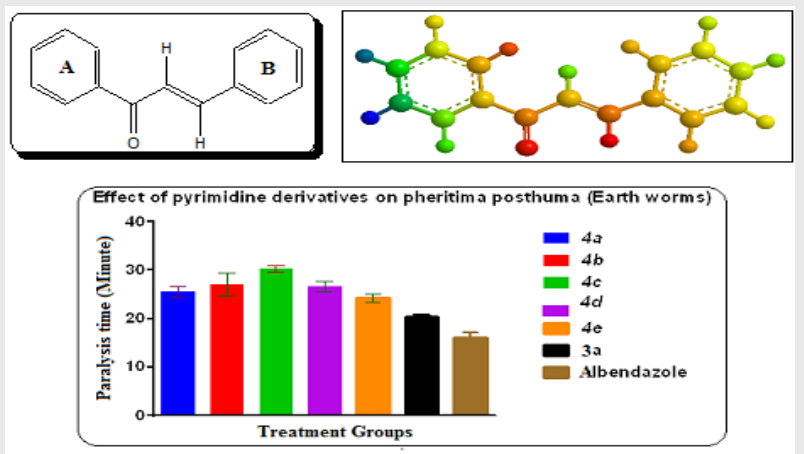

\section{About Authors}

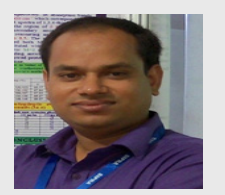

Biswa Mohan Sahoo: Is presently working as Associate professor and HOD in Vikas college of pharmacy, Vissannapeta, Andhra pradesh. He is experienced in teaching organic, inorganic, medicinal chemistry and pharmaceutical analysis at both undergraduate and post-graduate levels. He has guided around 20 PG students in their dissertation and carried out various research projects. His current area of interest involves computer assisted drug designing, microwave assisted synthesis and pharmacological screening of novel heterocyclic compounds. He has authored a book chapter entitled "Cyclodextrin as carrier for drug delivery systems" of Text Book of Pharmaceutical drug delivery systems and vehicles. He has published and presented various research papers at national and international levels. He is qualified in GATE-2005 (94.73 percentile) conducted by IIT Bombay and received A.I.C.T.E. fellowship. He is a life member of Association of Pharmacy Teachers of India (APTI) and scientific societies as well as serving the position of reviewer, editorial and advisory board member of various national and international journals.

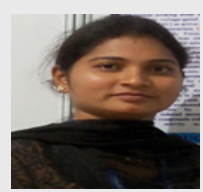

Mullangi Rajeswari: Is currently working as Assistant professor in Vikas college of pharmacy, Vissannapeta, Krishna district, Andhra pradesh. She is experienced in teaching organic, inorganic and medicinal chemistry at undergraduate level. Her research interest includes synthesis, characterisation and pharmaological evaluation of heterocyclic compounds. She has attended and presented research papers at several national levels.

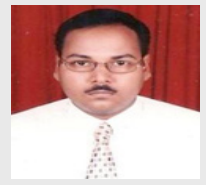

Jnyanaranjan Panda: He is working as an associate professor in Roland Institute of Pharmaceutical Sciences, Odisha, India. He is a life member of Association of Pharmacy Teachers of India (APTI). He has guided both PG and UG students in their research projects. He is expert in teaching organic, inorganic and medicinal chemistry. He has published research papers at various national and international levels.

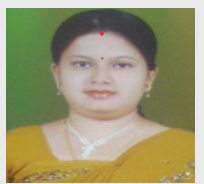

Binayani Sahoo: She is the research scholar in Department of Chemistry, M.V.R Degree College,Nuzvid, Krishna University, A.P, India. Her research area of interest is synthesis, characterisation and biological evaluation of heterocyclic compounds. She has published research papers at various national levels.

Cite this article: Sahoo BM, Rajeswari M, Jnyanaranjan P, Binayani S. Green Expedient Synthesis of Pyrimidine Derivatives via Chalcones and Evaluation of their Anthelmintic Activity. Indian $\mathrm{J}$ of Pharmaceutical Education and Research. 2017;51(4S):S700-S6. 